Medical Principles and Practice

Bader M. Al-Zaid

Sana S. Buhamra

A.H. Al-Ibrahim

Dahyat Abdalla Al-Salem Clinic, Kuwait

\section{Key Words}

Work satisfaction

Primary care

Family physicians

Kuwait

\title{
Factors for Job Satisfaction among Primary Care Physicians in Kuwait
}

\section{Abstract}

Objective: To explore factors affecting job satisfaction among primary care physicians in Kuwait amidst the various challenges in the aftermath of the Gulf war. These challenges are in terms of lower number of physicians and lesser number of reopened primary care centres post liberation. Methods: A selfadministered questionnaire covering various aspects of job satisfaction was prepared and distributed to a random sample of 185 primary care physician across the five governorates of Kuwait. Factor analysis was employed to ascertain factors underlying job satisfaction. Results: Nine common factors underlying job satisfaction explained $66.9 \%$ of the variance in the data. Generally, the physicians were dissatisfied with three factors: salary and promotion, relationship with superiors, and availability of resources. They were satisfied with the remaining six factors: intrinsic work factors, work surroundings, job enthusiasm, relationship with hospital doctors, relationship with colleagues, and finally comfort at work. These nine factors were related to certain demographic variables that were indicative of social structure. Kuwaiti non-family physicians were least dissatisfied with salary and promotion and nonKuwaiti family physicians were most dissatisfied with this factor. Conclusion: Nationality and specialty proved to be powerful predictors of satisfaction as well as other variables. This is expected because of the advantages Kuwaities have over non-Kuwaities in terms of salary and promotion, and the disadvantages facing family practitioners being, in general, better qualified to do the job, though not appreciated.

\begin{tabular}{ll}
\hline KARGER & @ 1998 S. Karger AG, Basel \\
Fax +41 61 306 12 34 & 1011-7571/98/0072-0109\$15.00/0 \\
$\begin{array}{l}\text { E-Mail karger@karger.ch } \\
\text { www.karger.com }\end{array}$ & $\begin{array}{l}\text { This article is also accessible online at: } \\
\text { http://BioMedNet.com/karger }\end{array}$
\end{tabular}

Dr. Bader M. Al-Zaid

Family Practitioner

Dahyat Abdalla Al Salem Clinic

PO Box 38253

72253 Kuwait City (Kuwait) 


\section{Introduction}

Although job satisfaction among the medical body is extensively studied in the West, the same is hardly true in Kuwait [1-10]. Conducting a research in Kuwait among primary care physicians is of paramount importance due to two main reasons. First, to the best of our knowledge, no previous study has been conducted in Kuwait with regard to job satisfaction in the health field, although some references are found on job satisfaction in relation to other professions $[11,12]$. Second, the necessity to address the effect of nationality at the level of satisfaction, which is quite unique to the Arabian peninsula in general and to Kuwait in particular.

Health care in Kuwait is organized and run by the government, although private clinics and hospitals are also available competing with government health units in providing quality health care. To improve the quality of public health care and to increase access to services, the government of Kuwait has developed a unique medical system for public health service. Three broad types of services are distinguished: primary health care, general hospitals (secondary care), and specialized centres (tertiary care). Over the last three decades, the primary care service was provided in the so-called traditional system where there was a physician for men, another for women and a paediatrician in each clinic. By the mid 80s the family medicine system was introduced into primary health care in Kuwait as a parallel to the traditional system. Clinic services were then provided by a single physician to the whole family. In recent years, the concept of primary health care has been challenged by a number of factors especially in the aftermath of the Gulf war. Tremendous pressure is being put on primary care physicians in terms of high patient volume, antisocial working hours, demoralization, rising ex- pectations of patients, strained relationships with superiors and colleagues at the hospital, and lack of career trajectories. It seems that many of these negative feelings are also echoed by primary care physicians in other countries in the West [13,14].

The social structure of Kuwaiti society is unique in many ways. In spite of the small population, estimated to be $1,378,613$, local Kuwaiti citizens are only a fraction of the population of $655,820(41.6 \%)$. The rest are expatriate workers and their dependents who are brought to Kuwait to work on a contract basis, many of them for an extended period of several years. In the health care profession Egyptians constitute the majority of physicians outnumbering even the local Kuwaiti physicians. The three groups of physicians targeted in this study are Kuwaiti, Egyptian, and physicians of other nationalities. The aims of this study are thus twofold. The first is to determine those factors which underlie job satisfaction for primary health care physicians in Kuwait, and how they compare with factors from similar studies in other countries. The second is to test differences between family (FP) and non-family (non-FP) physicians with differing demographic characteristics, particularly differences among Kuwaiti and non-Kuwaiti groups.

\section{Methods}

Generation of the Questionnaire

The development of the questionnaire has passed through several stages. The first stage involved a review of the literature to generate a list of identified job satisfaction aspects. The initial aspects were [5, 9, 14]: general satisfaction, relationship with superiors, relationship with colleagues, promotion, salary, and availability of resources. Next, a number of primary care physicians were asked to list their feelings and impressions regarding different aspects of job satisfaction. Considering these two steps a modified list of statements was formulated. A review of job satisfac- 
tion questionnaires for other professions resulted in a few modifications to the compiled items. The list was then reviewed and modified by experts in the field of measurement at the Kuwait University. An initial draft of the questionnaire was piloted among a limited number of physicians working in the non-primary care field to validate the wording of the items. Thirty-six items that measured on a 5-point Likert scale were included in the final version of the questionnaire in addition to the ten items on demographic variables.

\section{Data Collection}

According to the list released in December 1995 by the Head of the Department of the primary care unit in Kuwait, there are $53 \mathrm{FP}$ and 495 non-FP in all 64 centres in Kuwait. Since the number of FP is relatively small and as they are the focus of this study, it was decided to include all members of the population in the study. Thirty percent of the non-FP population was sampled. This resulted in sample sizes of 53 and 150 , respectively, from the two populations. The selected physicians were contacted individually in their centres by research assistants. During these visits the participants were updated on the importance of providing accurate data that truly reflect their attitudes. To ensure objectivity, the respondents were allowed to be anonymous and the questionnaires were collected through research assistants who were trained to collect reliable data. Follow-up techniques such as repeated visits to the centres and personal calls to all individuals in the sample were also used to achieve maximum rate of response returns. The return rate was indeed remarkable. Of the 53 questionnaires sent out to all FPs, 47 responded $(88.68 \%)$, and of the 150 sent out to nonFPs in the sample, 138 responded (92\%). To make sure that no bias was introduced from the non-respondent group, a final check was made on the non-respondent group searching for any systematic pattern with respect to demographic and social variables such as gender, nationality, and qualifications.

\section{Statistical Analysis}

The statistical technique factor analysis was used to identify factors defining the underlying dimensions for job satisfaction. The analysis was carried out on SPSS computer software. Several steps were taken in the process of factor generation. First, the analysis was carried out on all 36 items using the principal component method for factor determination. The factors thus derived explained maximum amount of variance in the data. The criterion for the number of factors considered was chosen to be number of eigenvalues larger than unity. Next, the assumptions of the factors model were checked and the appropriateness of the model was evaluated. Then a first attempt at interpreting the factors was made followed by a rotation of the solution in the factor space to enhance interpretation. The Varimax criterion was selected as the basis for rotating the solution because it often results in solutions with simple structure, i.e. solutions most easily interpreted [15].

The Kruskal-Wallis test was used to detect differences between groups defined by certain demographic variables. This is a non-parametric statistical test appropriate for testing the statistics between groups whose distributions are unknown. Whenever significant differences between the groups were detected, the analysis was followed by a multiple comparison procedure to determine which group(s) was/were responsible for the observed differences [16].

\section{Results and Discussion}

\section{Summary Statistics}

The sample comprised 114 (61.6\%) male physicians and $71(38.4 \%)$ female physicians: $41(22.2 \%)$ physicians aged less than 35 years, $62(33.5 \%)$ physicians aged between 35 and $39,40(21.6 \%)$ physicians aged between 40 and 44 , and finally $42(22.7 \%)$ physicians aged 45 years or more. One hundred and sixty-three $(88.1 \%)$ of the physicians were married, $16(8.6 \%)$ were single and $6(3.2 \%)$ were divorced or widowed. Egyptian physicians comprised the largest single nationality group, 60 (32.4\%) followed by Kuwaitis, 44 (23.8\%), and physicians from all other nationalities in the last group totalled $81(43.8 \%)$. In terms of qualifications, 47 (25.4\%) physicians held $\mathrm{RCGP} /$ Kuwait, which is a postgraduate degree equivalent to $\mathrm{PhD}$ degree, 45 (24.3\%) physicians held a Master's degree, 35 (18.9\%) physicians held a diploma, and 58 (31.4\%) physicians had no higher qualifications. All the 47 RCGP/Kuwait holders were FPs. The distribution of the physicians over the governorates of Kuwait was as follows: $50(27 \%)$ in Ahmadi governorate, 45 (24.3\%) in Hawalli, 
Table 1. Percentages of physicians for pairs of demographic variables

\begin{tabular}{|c|c|c|c|c|c|}
\hline \multirow[t]{2}{*}{ Demographic variable } & \multicolumn{3}{|c|}{ Nationality } & \multicolumn{2}{|l|}{ Specialty } \\
\hline & Kuwaiti & Egyptian & other & non-FP & FP \\
\hline \multicolumn{6}{|l|}{ Nationality } \\
\hline Kuwaiti & & & & 29.5 & 70.5 \\
\hline Egyptian & & & & 83.3 & 16.7 \\
\hline Other & & & & 95.1 & 4.9 \\
\hline \multicolumn{6}{|l|}{ Age } \\
\hline Less than 35 years & 34.1 & 17.1 & 48.8 & 73.2 & 26.8 \\
\hline $35-39$ years & 29.0 & 29.0 & 41.9 & 66.1 & 33.9 \\
\hline 40-44 years & 25.0 & 35.0 & 40.0 & 70.0 & 30.0 \\
\hline 45 and more & 4.8 & 50.0 & 45.2 & 97.6 & 2.4 \\
\hline \multicolumn{6}{|l|}{ Gender } \\
\hline Male & 15.8 & 34.2 & 50.0 & 85.1 & 14.9 \\
\hline Female & 36.6 & 29.6 & 33.8 & 60.6 & 39.4 \\
\hline \multicolumn{6}{|l|}{ Marital status } \\
\hline Single & 31.3 & 18.8 & 50.0 & 81.3 & 18.8 \\
\hline Married & 23.3 & 32.5 & 44.2 & 74.8 & 25.2 \\
\hline Other & 16.7 & 66.7 & 16.7 & 83.3 & 16.7 \\
\hline \multicolumn{6}{|l|}{ Primary care experience } \\
\hline $1-5$ years & 16.9 & 29.9 & 53.2 & 87.0 & 13.0 \\
\hline $6-10$ years & 47.8 & 13.0 & 39.1 & 54.3 & 45.7 \\
\hline $11-15$ years & 23.5 & 38.2 & 38.2 & 70.6 & 29.4 \\
\hline 16 and more & 3.6 & 64.3 & 32.1 & 85.7 & 14.3 \\
\hline \multicolumn{6}{|l|}{ Qualifications } \\
\hline $\mathrm{BSc}$ & 13.8 & 29.3 & 56.9 & 100.0 & \\
\hline Diploma & 5.4 & 48.6 & 45.9 & 100.0 & \\
\hline MSc & 6.7 & 33.3 & 60.0 & 100.0 & \\
\hline $\mathrm{PhD}$ & 68.9 & 22.2 & 8.9 & & 100.0 \\
\hline \multicolumn{6}{|l|}{ Occupation } \\
\hline General practitioner & 3.2 & 35.5 & 61.3 & 100.0 & \\
\hline Principal & 50.0 & 43.8 & 6.3 & 100.0 & \\
\hline FP & 58.3 & 25.0 & 16.7 & 5.6 & 94.4 \\
\hline Paediatrician & 3.6 & 35.7 & 60.7 & 100.0 & \\
\hline Principal and family & 91.7 & 8.3 & & 8.3 & 91.7 \\
\hline \multicolumn{6}{|l|}{ Salary } \\
\hline Less than $700 \mathrm{KD}$ & 1.9 & 37.0 & 61.1 & 90.7 & 9.3 \\
\hline 700-900 KD & 8.1 & 35.5 & 56.5 & 90.3 & 9.7 \\
\hline $901-1,200 \mathrm{KD}$ & 17.6 & 47.1 & 35.3 & 70.6 & 29.4 \\
\hline $1,201-1,500 \mathrm{KD}$ & 85.0 & 10.0 & 5.0 & 35.0 & 65.0 \\
\hline More than $1,500 \mathrm{KD}$ & 100.0 & & & 26.7 & 73.3 \\
\hline \multicolumn{6}{|l|}{ Specialty } \\
\hline Non-FP & 9.3 & 35.7 & 55.0 & & \\
\hline FP & 68.9 & 22.2 & 8.9 & & \\
\hline
\end{tabular}


$43(23.2 \%)$ in Ameeri, 36 (19.5\%) in Farwania, and $11(5.9 \%)$ in Jahra. In table 1 percentages are listed for each nationality group and specialty group with groups being formed by other demographic variables.

\section{Validity and Reliability}

The development of the measuring instrument for this study was built on previously established dimensions of job satisfaction [14]. Other dimensions that were thought to account for aspects of job satisfaction unique to the socio-economic structure of Kuwaiti society were also included. Content validity for the instrument was obtained by soliciting judgements of experts on a list of items covering all aspects of job satisfaction. For reliability, the Cronbach's alpha coefficient was calculated for all 36 items on the list, and was found to be 0.9332 , showing a high level of internal consistency (or reliability).

\section{Factors for Job Satisfaction}

The analysis revealed nine factors explaining $66.9 \%$ of the common variance in the data. The interpretation of the factors was based only on items with large factor loadings $(>0.4)$. Initially we found two items failing to meet this requirement, one with a loading below 0.4 and another with a loading around 0.4 and on more than one factor. Both of these items were deleted and the factor analysis was rerun on the reduced set of 34 items. In table 2 the nine factors were listed based on the reduced set of items along with the factor loadings and the alpha coefficients of the factors. Looking at the items defining factor 1 , one notes that they relate mainly to the nature of the job itself and not to conditions external to the job. Thus, the label 'intrinsic work factor' was selected. Similarly, the factors 2-9 were labelled, respectively: 'relationship with superiors', 'salary and promotion', 'work surrounding', 'job enthusiasm', 'relationship with hospital doctors', 'relationship with colleagues', 'availability of resources', and 'comfort at work'.

The nine common factors in table 2 jointly account for about two thirds of the covariance in the data with factor 1 alone accounting for almost one third (32.6\%) of the covariance. Since the factors are independent it is possible to form subscales defined by items highly loaded on the factors and combine the subscales to obtain a scale for job satisfaction. One way to form a subscale is by computing the weighted average of the items that are highly loaded on the given factor with weights proportional to the loadings. The weighted average was used as opposed to the usual average to reflect the relative importance of the items with respect to the given factor. Unlike the factor scores which are standardized, the average and the weighted average are both measured on the same scale as the items. This has the advantage of easy interpretation of the results.

To test for differences between subscales, we performed one-way ANOVA and obtained $F$ value 98.54 , and $p$ value $<0.0001$ showing that the differences in the subscale means are highly significant. The subscale means (and their standard deviations) were 3.24 (0.055), $3.8(0.074), 2.32(0.06), 3.78(0.061), 3.68$ $\begin{array}{llll}(0.059), & 2.87 \quad(0.066), \quad 3.97 \quad(0.055), 2.88\end{array}$ (0.073), and 4.15 (0.06), respectively. The Tukey's b paired multiple comparisons method [17] was applied on the means to identify subscales with significantly different means. Factors 6 and 8 were grouped together as well as factors 4 and 5 and finally factors 7 and 9 . The ordered means ranging from the smallest to the largest were for factors $3,6,8,1,5,4,7$, and 9 with the first three ordered factors on the dissatisfied side (means $<3$ ), and the last six ordered factors on the satisfied side. It is clear from this configuration that physicians were mostly dissatisfied with factor 3 (salary 
Table 2. Factor analysis of statements relating to job satisfaction

\begin{tabular}{|c|c|c|c|}
\hline & & Factor loading & Alpha \\
\hline \multirow[t]{12}{*}{ Factor 1: } & Intrinsic work factors (11.07-32.6\%) & & 0.8913 \\
\hline & My work corresponds well with my previous experience & 0.7353 & \\
\hline & The nature of my work is variable and routineless & 0.7262 & \\
\hline & My ambitions are fulfilled in my work & 0.7000 & \\
\hline & I enjoy my work & 0.6824 & \\
\hline & I have enough freedom to conduct my work the way I like & 0.6602 & \\
\hline & Daily number of patients in the clinic is appropriate & 0.6435 & \\
\hline & I am satisfied with my job & 0.6262 & \\
\hline & The results of my work are clearly tangible & 0.6221 & \\
\hline & My patients look at me with respect & 0.5479 & \\
\hline & I feel secure at work & 0.4945 & \\
\hline & The nature of my work requires solving difficult problems & 0.4941 & \\
\hline \multirow[t]{6}{*}{ Factor 2: } & Relationship with superiors (2.75-8.1\%) & & 0.9416 \\
\hline & My superior is a democratic person & 0.9072 & \\
\hline & My superior is qualified in his/her work & 0.8884 & \\
\hline & My superior is able to distribute job tasks clearly & 0.8873 & \\
\hline & I am satisfied with the way my superior's issuing of the orders & 0.7791 & \\
\hline & I feel I am respected and honoured by my superiors & 0.7021 & \\
\hline \multirow[t]{5}{*}{ Factor 3: } & Salary and promotion $(1.96-5.6 \%)$ & & 0.7423 \\
\hline & The chances of promotion are equal and fair to everyone & 0.7905 & \\
\hline & The chances of promotion are good in my work & 0.7483 & \\
\hline & The future of my present occupation is clear & 0.5752 & \\
\hline & My salary is commensurate with the work I do & 0.5562 & \\
\hline \multirow[t]{5}{*}{ Factor 4: } & Job enthusiasm (1.41-4.1\%) & & 0.6542 \\
\hline & I have no intention to change my specialty & 0.7396 & \\
\hline & I am satisfied with my social status in comparison to other medical specialties & 0.5962 & \\
\hline & I have no intention to resign or quit my job & 0.5659 & \\
\hline & $\begin{array}{l}\text { Choose the phrase that best describes your feelings about your work } \\
\text { (enthusiastic about it, love it, like it, don't care about it, hate it) }\end{array}$ & 0.5050 & \\
\hline \multirow[t]{4}{*}{ Factor 5: } & Work surroundings (1.26-3.7\%) & & 0.7036 \\
\hline & Assistant staff (nurses + pharmacists) are qualified & 0.7344 & \\
\hline & The job load assigned to me is fair compared with my colleagues & 0.6333 & \\
\hline & The current (calls/shifts) duty system is appropriate & 0.4832 & \\
\hline \multirow[t]{3}{*}{ Factor 6: } & Relationship with hospital doctors (1.24-3.7\%) & & 0.5951 \\
\hline & The professional relationship between me and hospital physicians is based on mutual respect & 0.7723 & \\
\hline & It is easy to follow up patients after they have been referred to specialized hospitals & 0.7004 & \\
\hline \multirow[t]{3}{*}{ Factor 7: } & Relationship with colleagues (1.19-3.5\%) & & 0.6555 \\
\hline & The relationship with my colleagues at work is friendly & 0.8340 & \\
\hline & The people I work with care personally about me & 0.6666 & \\
\hline \multirow[t]{2}{*}{ Factor 8: } & Availability of resources (1.16-3.4\%) & & - \\
\hline & The medication I need to prescribe are available in the clinic pharmacy & 0.7466 & \\
\hline \multirow[t]{3}{*}{ Factor 9: } & Comfort at work (1.02-3.0\%) & & 0.1289 \\
\hline & The patients' recurrent request for sick leaves is a source for anxiety & 0.8120 & \\
\hline & Office hours are sufficient to complete job tasks & 0.5323 & \\
\hline
\end{tabular}

Al-Zaid/Buhamra/Al-Ibrahim 
and promotion) and mostly satisfied with factors 7 and 9 (relationship with colleagues and comfort at work). Though factor 1 (intrinsic work factors) was on the satisfied side, the mean of this factor was close to neutral point 3 , showing only a slight positive attitude in comparison with means of other factors. For practical reasons this factor will be interpreted as neutral in what follows.

The results of this analysis apply to the general population of physicians working in primary care. However, to get more insight into the interpretation of these results, the factors were compared between groups of physicians within the general population which were formed based on certain demographic variables that reflected the social structure of the population.

\section{Effects of Social Groups}

To evaluate the effects of social groups on the factors, the subscale means were tested for significance on groups defined by certain demographic variables using the Kruskal-Wallis test statistic. Table 3 lists the group means and the significant ones are signified by asterisks. In the case of variables defining exactly two groups such as gender the means are directly comparable. For example, from the table we find that male physicians were more satisfied with the 2nd factor (relationship with superiors) than female physicians, and similarly for the 5th factor (work surroundings). On the other hand, the means for variables defining more than two categories were compared using multiple comparisons analysis and a summary of the main results follows.

Nationality. It was found that Kuwaiti physicians, in comparison with the other two groups of nationality, were less satisfied with two factors (relationship with superiors, work surroundings) and least dissatisfied with one factor (salary and promotion). Also, both Ku- waiti and Egyptian physicians were more satisfied than the third group on the intrinsic work factors. This is to be expected since Kuwaiti physicians have different expectations of their jobs and have better job security and better opportunities for career development than non-Kuwaiti physicians.

Total Experience and Primary Care Experience. Groups defined by each of these two demographic variables were significantly different only on one factor, factor 8 for total experience, and factor 2 for primary care experience. These variables were omitted from table 3. A brief description of the results is included here. For total experience, the analysis showed that the least experienced physicians were most dissatisfied with the availability of resources. One may argue that a young physician needs some time to become acclimatized to the new environment where he/she needs to develop new skills amidst limited facilities [18]. The analysis also showed that for the second variable, experience in primary care, the more experienced physicians were least satisfied with relationships with superiors.

Qualifications. PhD holders were least satisfied with relationship with superiors and work surroundings and were most dissatisfied with relationship with hospital doctors.

Occupation. Principals were most satisfied with relationship with superiors and with work surroundings, and least dissatisfied with salary and promotion.

Salary. The least paid physicians were most dissatisfied with salary and promotion whereas the most paid physicians were least dissatisfied with salary and promotion. The most paid physicians were also least satisfied with relationship with superiors.

Specialty. FPs were less satisfied than the non-FPs with respect to relationship with their superiors and work surroundings. They were also more dissatisfied with respect to 
Table 3. Subscale means for levels of certain demographic variables

\begin{tabular}{|c|c|c|c|c|c|c|c|}
\hline Demographic variable & $\begin{array}{l}\text { Intrinsic } \\
\text { work } \\
\text { factors }\end{array}$ & $\begin{array}{l}\text { Relationship } \\
\text { with } \\
\text { superiors }\end{array}$ & $\begin{array}{l}\text { Salary } \\
\text { and } \\
\text { promotion }\end{array}$ & $\begin{array}{l}\text { Job } \\
\text { enthu- } \\
\text { siasm }\end{array}$ & $\begin{array}{l}\text { Work } \\
\text { surroun- } \\
\text { dings }\end{array}$ & $\begin{array}{l}\text { Relationship } \\
\text { with hospital } \\
\text { doctors }\end{array}$ & $\begin{array}{l}\text { Relationship } \\
\text { with } \\
\text { colleagues }\end{array}$ \\
\hline Gender & & $* *$ & & & $* * *$ & & $*$ \\
\hline Male & 3.24 & 3.93 & 2.38 & 3.85 & 3.83 & 2.92 & 4.06 \\
\hline Female & 3.24 & 3.59 & 2.22 & 3.67 & 3.43 & 2.78 & 3.83 \\
\hline Nationality & $* *$ & $*$ & $* *$ & & $*$ & & \\
\hline Kuwaiti & 3.38 & 3.45 & 2.50 & 3.73 & 3.45 & 2.70 & 4.09 \\
\hline Egyptian & 3.37 & 3.95 & 2.40 & 3.84 & 3.80 & 2.86 & 3.88 \\
\hline Other & 3.07 & 3.88 & 2.15 & 3.76 & 3.70 & 2.97 & 3.97 \\
\hline Qualifications & $* *$ & $*$ & $* *$ & & $* * *$ & $* *$ & \\
\hline $\mathrm{BSc}$ & 3.31 & 3.91 & 2.33 & 3.71 & 3.81 & 3.01 & 4.04 \\
\hline Diploma & 3.40 & 3.83 & 2.64 & 3.88 & 3.87 & 3.13 & 3.76 \\
\hline $\mathrm{MSc}$ & 2.97 & 4.04 & 2.20 & 3.80 & 3.73 & 2.87 & 3.89 \\
\hline $\mathrm{PhD}$ & 3.32 & 3.40 & 2.15 & 3.78 & 3.29 & 2.49 & 4.12 \\
\hline Occupation & $* *$ & $* * *$ & $* * *$ & & $* *$ & $* *$ & \\
\hline General practitioner & 3.17 & 3.93 & 2.31 & 3.74 & 3.76 & 3.07 & 3.92 \\
\hline Principal & 3.64 & 4.24 & 2.94 & 4.07 & 4.13 & 2.92 & 4.15 \\
\hline $\mathrm{FP}$ & 3.37 & 3.69 & 2.08 & 3.87 & 3.38 & 2.53 & 4.21 \\
\hline Paediatrician & 3.06 & 3.65 & 2.22 & 3.67 & 3.62 & 2.77 & 3.70 \\
\hline Principal and family & 3.35 & 2.85 & 2.51 & 3.70 & 3.40 & 2.54 & 3.99 \\
\hline Salary & $*$ & $*$ & $* *$ & $*$ & $*$ & & \\
\hline Less than $700 \mathrm{KD}$ & 3.00 & 3.85 & 2.03 & 3.56 & 3.52 & 2.79 & 3.85 \\
\hline 700-900 KD & 3.34 & 4.02 & 2.30 & 3.97 & 3.84 & 3.02 & 4.05 \\
\hline $901-1,200 \mathrm{KD}$ & 3.38 & 3.71 & 2.53 & 3.86 & 3.78 & 2.94 & 3.95 \\
\hline $1,201-1,500 \mathrm{KD}$ & 3.25 & 3.65 & 2.39 & 3.83 & 3.37 & 2.44 & 4.01 \\
\hline More than $1,500 \mathrm{KD}$ & 3.37 & 3.09 & 2.74 & 3.58 & 3.72 & 2.94 & 4.05 \\
\hline Specialty & & $* *$ & $*$ & & $* * *$ & $* * *$ & \\
\hline Non-FP & 3.22 & 3.93 & 2.37 & 3.78 & 3.80 & 2.99 & 3.92 \\
\hline FP & 3.32 & 3.40 & 2.15 & 3.78 & 3.29 & 2.49 & 4.12 \\
\hline \multicolumn{8}{|c|}{$\begin{array}{l}\text { * Significant at } 0.10 \text { level. } \\
\text { ** Significant at } 0.05 \text { level. } \\
\text { *** Significant at } 0.01 \text { level. }\end{array}$} \\
\hline
\end{tabular}

relationship with hospital doctors and salary and promotion. Also, FPs were less satisfied with work surroundings than the non-FPs. It seems that FPs - all being PhD holders in contrast to non-FPs - believed they were not appreciated well by their superiors and fellow colleagues at hospitals, although by training they were highly qualified and better suited physicians to carry out the requirements of a job in primary care practice.

\section{Nationality and Specialty as Social \\ Indicators}

We now turn to the effect of interactions of the social groups on the factors. It is clear from table 1 that nationality and specialty 


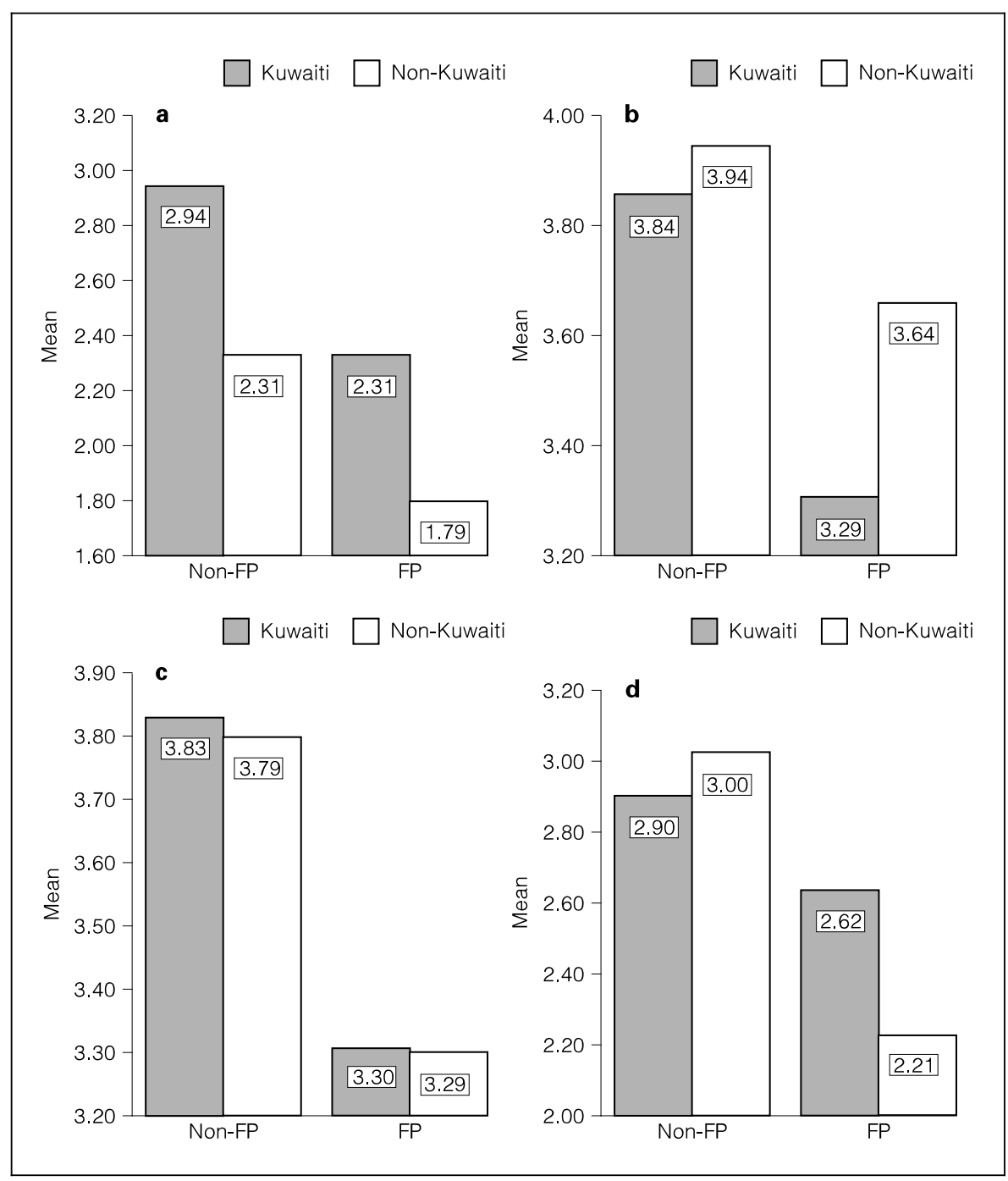

Fig. 1. Means satisfaction for factors by nationality and specialty. a Salary and promotion. b Relationship with superiors. c Work surroundings. d Relationship with hospital doctors.

interact with each other and with other variables. For example, Kuwaiti physicians constituted more than two thirds $(68.9 \%)$ of the highly qualified physicians (PhD holders/ family), were paid better than other physicians $(91.4 \%$ earned more than KD 1,200), and more than two thirds (67.9\%) of the highly ranked physicians (principal/principal and family) were Kuwaitis. To reveal the effects of such interaction we paired nationality (after recoding it into Kuwaitis and non-Kuwaitis) with a second variable and studied their joint effect on the mean satisfaction/dissatisfaction of the factors. We found that the third factor, salary and promotion, was highly significant on the joint groups formed by nationality and 
specialty. In fact, as illustrated in the bar chart in figure 1a, Kuwaiti non-FPs were least dissatisfied with this factor and non-Kuwaiti FPs were most dissatisfied with the factor. This is expected because of the advantages Kuwaitis have over non-Kuwaitis in terms of salary and promotion and because of the disadvantages the FPs face being, in general, better qualified to do the job but not well appreciated. It is to be recalled that in the Kuwaiti society nationality is not only an indicator of ethnic diversity [19], but also a discriminative value for salary and promotion.

Finally, in figure 1b-d, we constructed the bar charts for factors 2, 5, and 6 versus the groups formed by combinations of nationality and specialty. Similar charts were also constructed for combinations of pairs of other variables, though not reported here, with similar results to above, confirming our previous remark that nationality and specialty were powerful predictors of the other variables and good indicators of social structure of Kuwait society.

\section{Conclusion}

The analysis of the ratings on the questionnaire developed to evaluate job satisfaction among primary care physicians in Kuwait revealed nine factors related to job satisfaction. These factors explained about two thirds of the common variance in the data. Generally, the physicians were dissatisfied with three factors: salary and promotion, relationship with superiors, and availability of resources. They were satisfied with the remaining six factors: intrinsic work factors, work surroundings, job enthusiasm, relationship with hospital doctors, relationship with colleagues, and finally comfort at work. The nine factors were related to certain demographic variables that were indicative of social structure and we found that Kuwaiti non-FPs were least dissatisfied with salary and promotion and nonKuwaiti FPs were most dissatisfied with this factor.

Apart from the introduction of the family practice system in the mid 80 s, the working conditions and standings of general practitioners in Kuwait have not improved much over the past 20 years. Subsequently, it was initially expected that job satisfaction among family practitioners in general and Kuwaitis in particular will be low. The results came to confirm this initial expectation. It is suggested that, unless immediate and decisive measures are taken to correct this trend of the professional practice, symptoms of professional burnout will soon surface among the physicians in the practice. This is supported by other studies relating professional burnout with low levels of job satisfaction and poor job attitudes [20].

Our findings have several implications. First, Kuwaiti physicians and FPs should have better access to their superiors and colleagues at hospitals. This implies that they be recognized for professionalism and competence by means of regular scientific meetings and improved feedback system. Second, there is an urgent need to improve the work conditions and to provide competitive services by elevating the standards for recruiting the assisting staff in primary care clinics. Finally, a revised policy of salary and promotion for non-Kuwaiti physicians need to be worked out to keep the general practice an attractive place for young expatriate physicians. 


\section{References}

1 Stamps PL, Piedmont EB, Slavitt DB, Hasse AM: Measurement of work satisfaction among health professionals. Med Care 1978;16:337352.

2 Booth M, Smith SF: Job satisfaction among resident medical officers. N Z Med J 1990;103:425-427.

3 Branthwaite A, Ross A: Satisfaction and job stress in general practice. Fam Pract 1988;5:83-93.

4 Chuck JM, Nesbitt TS, Kwan J, Kam SM: Is being a doctor still fun? West J Med 1993;6:665-669.

5 Cooper C, Usha R, Faragher B: Mental health, job satisfaction, and job stress among general practitioners. BMJ 1989;298:366-370.

6 Grol R, Mokkink H, Smits A, Van Eijk J, Beek M, Mesker P, MeskerNeisten J: Work satisfaction of general practitioners and the quality of patient care. Fam Pract 1985;2: 128-134.
7 Kravitz RL, Linn L, Shapiro M: Physician satisfaction under the Ontario health insurance plan. Med Care 1990;28:502-512.

8 May H, Revicki D: Professional stress among family physicians. J Fam Pract 1985;20:165-171.

9 Makin P, Usharani R, Cooper C: Job satisfaction and occupational stress among general practitioners: A pilot study. J R Coll Gen Pract 1988;38:306-309.

10 Pathman DE, Konrad TR: Minority physicians serving in rural National Health Service Corps sites. Med Care 1996;34:439-453.

11 Al-Mosallam B: Job satisfaction of the national labor force in Kuwait (in Arabic). Kuwait Univ Press, 1993.

12 Al-Otaibi A: Relationship of personal variables to job satisfaction (in Arabic). J Public Adm 1992;76:91121.

13 Mc Bride M, Metcalfe D: General practitioners' low morale: Reasons and solutions (editorial). Br J Gen Pract 1995;May:227-229.
14 Skolnik N, Smith D, Diamond J: Professional satisfaction and dissatisfaction of family physicians. J Fam Pract 1993;37:257-263.

15 Harman HH: Modern Factor Analysis, ed 3. Chicago, University of Chicago Press, 1976.

16 Conover R: Practical Nonparametric Statistics. New York, Wiley, 1980.

17 SPSS Base 7.0 for Windows, User's Guide. Chicago, SPSS.

18 Fraser R: Clinical Method: A General Practice Approach. Oxford, Butterworth-Heinemann, 1993.

19 Meleis A: The health care system of Kuwait: The social paradoxes. Soc Sci Med 1979;13A:743-749.

20 Winefield HR, Anstey TJ: Job stress in general practice: Practitioner age, sex and attitudes as predictors. Fam Pract 1991;8:140-144. 